LANKESTERIANA 7: 151-153. 2003.

\title{
MICROPROPAGACIÓN Y CONSERVACIÓN DE ORQUÍDEAS MEXICANAS EN EL JARDÍN BOTÁNICO CLAVIJERO
}

\author{
VÍCTOR MANUEL SALAZAR ROJAS \& MARTÍN MATA ROSAS \\ Jardín Botánico Francisco Javier Clavijero, Instituto de Ecología, A.C. \\ Km 2.5 Carretera antigua a Coatepec 351 Xalapa 91070, Ver. México
}

El Jardín Botánico Clavijero (JBC) es poseedor de una colección de orquídeas mexicanas; alberga alrededor de 2915 plantas pertenecientes a más de 100 géneros y 329 especies. La misión principal del JBC es mantener una colección científica de plantas vivas, que permita realizar investigación, educación, difusión y propagación, así como contribuir a la conservación y el uso sustentable de especies endémicas o en peligro de extinción, particularmente de la flora regional, con énfasis en las especies del bosque mesófilo de montaña (BMM). Es importante resaltar que el BMM representa solamente el $2 \%$ del área de México y es uno de los ecosistemas más ricos, ya que posee el $60 \%$ de la especies de orquídeas del país (Hágsater \& Soto 2001). En nuestro territorio se distribuyen cerca de 1200 especies (Espejo et al. 2002), lo que representa aproximadamente el $6 \%$ del total mundial, de las cuales el $40 \%$ son endémicas (Soto 1994). México, al igual que otros países neotropicales poseedores de una gran orquideoflora, sufre de una severa alteración de ecosistemas, afectando a muchas poblaciones silvestres (Soto 1996). Este problema se agudiza aún más por la colecta ilegal de que son objeto las orquídeas, ocasionando que muchas de ellas se encuentren en peligro de extinción. Con base en lo anterior, el JBC, a través del Laboratorio de Cultivo de Tejidos Vegetales (CTV), está sumando esfuerzos para la propagación y conservación de orquídeas, como parte integral de la estrategia de conservación ex situ.

La primera etapa de esta estrategia ha sido el inicio de un banco de germoplasma in vitro de orquídeas, mediante la germinación de semillas y la evaluación de diferentes medios de cultivo (MS, MS 50\%, KC, $\mathrm{KC}$ modificado entre otros). Hasta la fecha se cuenta con alrededor de 25 especies que se han logrado establecer in vitro. A parir de ellas se están desarro- llando protocolos de micropropagación, los cuales servirán como base para iniciar el acercamiento a las comunidades poseedoras del recurso y promover su uso sustentable. A continuación se detalla el esquema seguido para Mormodes tuxtlensis Salazar, Cuitlauzina pendula La Llave \& Lex. y Lycaste skin neri (Batem. ex Lindl.) Lindl.

Se emplearon semillas maduras, obtenidas por polinización cruzada, provenientes de plantas pertenecientes a la colección de orquídeas del JBC. Las semillas se sembraron en medio KC (Knudson 1946) previamente esterilizadas con $\mathrm{H}_{2} \mathrm{O}_{2}(10.2$ volúmenes de oxígeno) por $10 \mathrm{~min}$. Cuando las semillas alcanzaron la fase de protocormo, fueron empleadas como fuente de explantes. Se ensayaron dos medios de cultivo: MS (Murashige \& Skoog 1962) y KC, adicionado con una combinación factorial de $\mathrm{N}^{6}$-benciladenina (BA) $(0,0.5,1,2$ y $3 \mathrm{mg} / \mathrm{l})$ y ácido $\alpha$-naftalen-acético (ANA) (0, 0.1 y $0.5 \mathrm{mg} / \mathrm{l}$ ). Todos los medios de cultivo se ajustaron a $\mathrm{pH}$ $5.0 \pm 0.1$ con $\mathrm{NaOH}$ y/o $\mathrm{HCl} 0.1$ previo a la adición de $5.5 \mathrm{~g} / 1$ de agargel. Los medios de cultivo se esterilizaron en autoclave a $120^{\circ} \mathrm{C}$ por $17 \mathrm{~min}$. Los cultivos se incubaron a $25 \pm 1^{\circ} \mathrm{C}$ con un fotoperíodo de $16 \mathrm{~h} \mathrm{luz}$ y una intensidad luminosa de $50 \mu \mathrm{Mol} / \mathrm{m} / \mathrm{s}$ proporcionada por dos lámparas fluorescentes de $75 \mathrm{~W}$.

Posterior al período de inducción (4 meses), los explantes se subcultivaron en sus respectivos medios de cultivo sin reguladores del crecimiento (medios basales), con el fin de que los brotes formados en el período de inducción se expresaran y desarrollaran. El registro de datos (número de brotes por explante) se realizó a los 4 meses.

Desarrollo ex vitro. Se seleccionaron plantas que presentaran hojas y raíces bien formadas, con una talla de 2 a $3 \mathrm{~cm}$ dependiendo del tratamiento de 
procedencia. Se procuró eliminar, con la ayuda de agua corriente, la totalidad del medio de cultivo sin dañar las raíces de las plántulas; posteriormente se transfirieron a condiciones de invernadero. Se ensayaron tres tipos de sustratos: 1) tepezil, 2) mezcla de corteza de pino, carbón de encino y tepezil $(3: 1: 1)$ y 3) Maquique (raíces de helecho arborescente) triturado. Se procuró mantener una humedad relativa alta durante los primeros 30 días, posteriormente se disminuyó gradualmente hasta que las plantas completaron su proceso de aclimatización. El registro de la sobrevivencia de las plantas se realizó mensualmente.

Resultados. Se han logrado establecer las mejores condiciones para la micropropagación y el establecimiento ex vitro de las tres especies bajo estudio. De manera general el empleo del medio de cultivo MS, a diferencia del medio $\mathrm{KC}$, favoreció la producción de brotes y raíces por explante, la talla alcanzada por los mismos, así como altos porcentajes de sobrevivencia ex vitro.

Para M. tuxtlensis, la vía de regeneración fue por organogénesis directa. Se obtuvo un promedio de 1.5 brotes por explante en el medio de cultivo MS adicionado con BA ( $3 \mathrm{mg} / \mathrm{l})$; en ese mismo tratamiento los brotes alcanzaron la mayor altura promedio (2.9 $\mathrm{cm})$. En el caso de $C$. pendula la principal respuesta fue la formación de cuerpos semejantes a protocormos (plbs), los cuales se desarrollaron en el medio de cultivo MS adicionado únicamente con BA (0.5 $\mathrm{mg} / \mathrm{l}$ ), así como en ausencia de reguladores de crecimiento, con 24.3 y 14.8 plántulas por explante, respectivamente. La talla promedio alcanzada por las plántulas después de 4 meses fue de $2-3 \mathrm{~cm}$. A pesar de que en el medio $\mathrm{KC}$ fue donde se logró la mayor formación de plántulas por explante (28.8), la talla alcanzada fue mucho menor $(0.9 \mathrm{~cm})$. Cabe destacar que las plántulas originadas en este medio presentaron una ligera clorosis.

La obtención de plántulas de L. skinneri se logró a través de organogénesis directa. El mayor promedio de plántulas por explante (16.4) se obtuvo en el medio MS adicionado únicamente con ANA (0.5 $\mathrm{mg} / \mathrm{l}$ ), alcanzando una talla promedio de $3.4 \mathrm{~cm}$.

La sobrevivencia ex vitro al parecer estuvo influenciada por el medio de cultivo; es decir, las plántulas obtenidas a partir de medio de cultivo $\mathrm{KC}$ presentaron porcentajes de sobrevivencia muy bajos, $4.7 \%$ en $L$. skinneri; 2.7 en $C$. pendula y nulos en el caso de $M$. tuxtlensis.

La sobrevivencia fue mayor a partir de plántulas provenientes de los diferentes tratamientos con medio de cultivo MS. Los mayores porcentajes de sobrevivencia se obtuvieron en las plántulas sembradas en la mezcla de corteza de pino, carbón de encino y tepezil (3:1:1), con una sobrevivencia de $89 \%, 76 \%$ y $60.1 \%$ en M. tuxtlensis, C. pendula y L. skinneri, respectivamente, menor en los sustratos con tepezil y maquique.

En México el maquique es ampliamente utilizado como sustrato para el cultivo de orquídeas, lo que ha ocasionado una sobrecolecta de estas especies de helechos arborescentes, llevándolas en muchos casos al borde de extinción. La utilización de sustratos alternativos, que favorezcan el cultivo de orquídeas, disminuirá la utilización del maquique, con lo que indirectamente se estará contribuyendo a su conservación.

Existen poco trabajos enfocados a la propagación y conservación de especies de orquídeas mexicanas, por lo que haber logrado establecer protocolos de cultivo in vitro y ex vitro de las tres especies estudiadas, con alto potencial ornamental, es una de las principales aportaciones del presente trabajo, además de ofrecer una alternativa económica real de este recurso poco explotado y crear conciencia sobre la importancia de mantener y cuidar los ecosistemas que albergan esta riqueza.

Es conocido que el empleo de la micropropagación de especies, tales como las orquídeas, representa uno de los medios más efectivos para conservar y salvaguardar las poblaciones silvestres, por lo que el desarrollo de paquetes tecnológicos, que puedan ser adoptados por horticultores, comunidades organizadas e interesadas en la explotación racional de sus recursos, contribuye directamente a su conservación, disminuyendo en gran medida la presión de colecta de poblaciones silvestres (Koopowitz 1996).

LITERATURA CITADA

Espejo, S.A., C.J. García, F.A.R. López, M.R. Jiménez y S.L. Sánchez. 2002. Orquídeas de Morelos. Herbario AMO y Universidad Autónoma MetropolitanaIztapalapa. México. 315 p. 
Hágsater E. \& M.A. Soto Arenas. 2001 Orchid conservation in Mexico. In W.E. Higgins y Walsh (eds.), Orchid Conservation Proceedings, Selby Botanical Gardens Press, Sarasota. p. 18-22.

Knudson L. 1946. A new nutrient solution for germination of orchid seed. Amer. Orch. Soc. Bull. 15: $214-217$.

Koopowitz H. 1996. Conservation Strategy. In E. Hágsater y V. Dumont (eds.), Orchids-Status Survey and Consevation Action Plan. IUCN, Gland, Switzerland and Cambridge, UK. 11-47.
Murashige, T. \& F. Skoog. 1962. A revised medium for rapid growth and bioassays with tobacco tissue cultures. Physiol. Plant. 15: 473 - 497.

Soto A., M.A. 1994. Listado actualizado de las orquídeas de México. Orquídea (Méx) 11: 233-277.

Soto A., M.A. 1996. Regional Accounts. In E. Hágsater y V. Dumont (eds.), Orchids - Status Survey and Consevation Action Plan. IUCN, Gland, Switzerland and Cambridge, UK. 53-58.

Víctor Manuel Salazar Rojas es estudiante de la Benemérita Universidad Autónoma de Puebla. El presente trabajo forma parte del proyecto de tesis de Licenciatura en Biología. adnbic@go.com

Martín Mata Rosas es Investigador Asociado del Jardín Botánico Francisco Xavier Clavijero, del Instituto de Ecología, donde es responsable del Laboratorio de Cultivo de Tejidos Vegetales. matam@ecologia.edu.mx 